\title{
Hydroxylysine Measurement
}

National Cancer Institute

\section{Source}

National Cancer Institute. Hydroxylysine Measurement. NCI Thesaurus. Code C154767.

The determination of the amount of hydroxylysine present in a sample. 